\title{
Safety of glucosamine, examined on ants as models
}

\begin{abstract}
Arthritis is one of the most spread illnesses and is treated using essentially glucosamine. Since some years, the efficiency and even the safety of this drug is debated. Indeed, a placebo has often an effect similar to that of glucosamine, and in some cases, this drug appeared to induce cells' death. In the present work, we examined the ethological and physiological effects of glucosamine using ants as models. No severe adverse effect was found: the ants' sensitive perception, social relationship, cognition, learning and memory were not impacted by glucosamine consumption. Moreover, this drug leaded to no dependence, and its effect slowly vanished in about 14hours after weaning. Glucosamine only increased the ants' activity and locomotion. Body movements are known as being beneficial to patients suffering from arthritis. Therefore, we cautiously hypothesize that one potential beneficial effect of glucosamine may result from an increase of activity and locomotion it induces.
\end{abstract}

Keywords: cartilage, locomotion, movement, Myrmica sabuleti, osteoarthritis
Volume 3 Issue 3 - 2018

\author{
Marie-Claire Cammaerts,' Roger \\ Cammaerts $^{2}$ \\ 'Independent researcher, retired from the Biology of Organisms \\ Department, University of Brussels, Belgium \\ Independent researcher, retired from the Natural and \\ Agricultural Environmental Studies Department (DEMNA) of \\ the Walloon Region, Belgium
}

Correspondence: Marie-Claire Cammaerts, independent researcher, 27, Square du Castel Fleuri, I I 70 Bruxelles, Belgium, Tel 32267349 69;

Email mtricot@ulb.ac.be; mccammaerts@gmail.com

Received: August 08, 2018 | Published: August 24, 2018

\section{Introduction}

Arthritis, a disease characterized by cartilage wearing, is one of the most common illnesses, particularly in aged persons. Articular cartilage plays the role of shock absorber and joint bearing. Due to its avascular nature, its regeneration is very limited, the chondrocytes receiving nutrients only by diffusion from the surrounding tissue. ${ }^{1}$

Glucosamine, a compound naturally synthesized from glucose and glutamine in almost every human tissue, has several functions in joint tissues. Among others, it is a key element in the synthesis of glycoaminoglycan (GAG) and proteoglycans, components of the cartilage matrix and of the synovial fluid; it prevents collagen degeneration in chondrocytes and inhibits cartilage inflammatory processes. ${ }^{1}$ Arthritis is commonly treated by an oral intake of glucosamine, a complementary medication or nutritional supplement for the purpose of decreasing articulation pain as well as of slowing the development of the disease, i.e. inducing mechanisms devoted to cartilage maintenance and repair. ${ }^{2}$ The most used glucosamine preparations are its sulfate and hydrochloride salts. The advantage of the latter is that its compound purity reaches $99 \%$ because it does not require sodium and potassium for stability. Therefore, the standard dosage of $1,500 \mathrm{mg}$ per day of glucosamine hydrochloride $(\mathrm{GH})$ for human use corresponds to ca 2,600 mg of glucosamine sulfate (GS). ${ }^{3}$ Taken orally, both salts dissociate in the stomach by releasing the glucosamine molecule ${ }^{1}$ and have a similar bioavailability. ${ }^{4}$

The efficiency of glucosamine in the treatment of osteoarthritis is nowadays debated, although it was showed to have a positive effect on the cartilage turnover, as measured by a decrease of the amount of markers such as collagen type II degradation (CTX-II) in urine ${ }^{5}$ and cartilage oligomeric matrix protein (COMP) in blood serum. ${ }^{6}$ Some clinical studies conclude that, compared to a placebo, glucosamine has statistically a beneficial effect on the symptoms of osteoarthritis (pain, swelling and function, i.e. stiffness). This was observed with GS on the basis of 3 -year lasting trials ${ }^{7,8}$ (the latter trial having obtained up to $25 \%$ improvement) and during a 6 months trial for a $\mathrm{GH}$ and chondroitin combined treatment. ${ }^{9}$ Other studies conclude to no effect for GS over a 2-year trial ${ }^{10,11}$ or for GH, chondroitin or a combination of both over 2years. ${ }^{12,13}$ Network meta-analysis of literature concluded that neither GS nor GH, nor chondroitin, nor their combination reduce joint pain. ${ }^{14-16}$

Concerning the slowing of the degenerative process, the effect of GS was found to be beneficial though modest on basis of 3-year trials. ${ }^{7,8,17}$ Long-term treatment with GS could even significantly prevent the total replacement of a knee joint during the 5years followup after treatment discontinuation. ${ }^{18} \mathrm{~A}$ meta-analysis ${ }^{14}$ concluded that there was evidence for improved joint function with GS taken during 6 months. On the contrary, other studies concluded to no beneficial effect of GS over 2years. ${ }^{10,11,19}$ A network meta-analysis examining 9 trials ${ }^{15}$ came to the same conclusion.

On the other hand, clinical studies concluded that the safety and treatment tolerance of long-term administrations of $\mathrm{GS}^{17} \mathrm{GH}^{9,13}$ or of either of these glucosamine salts can be considered as good, ${ }^{20}$ with no toxic patterns for GS. ${ }^{8}$ However, it has been shown that injected at high dose in rats ${ }^{21}$ or humans, ${ }^{22}$ glucosamine (preparation not specified) lowers the plasma insulin level and thus recapitulates metabolic features of diabetes. In vitro, it inhibits the pancreas $\beta$-cell glucokinase activity, ${ }^{21}$ and at much higher dose than that given to humans, it stimulates the apoptosis of the pancreas $\beta$-cells. ${ }^{23}$ Yet, given orally at standard dose $(1,500 \mathrm{mg}$ /day) during 6 weeks to humans and compared to a placebo, GH did not significantly cause insulin resistance or vascular dysfunction in healthy lean subjects or worsen these aspects in obese individuals. ${ }^{4}$

According to its debated efficiency and potential dangerousness, we intended to examine the effects of glucosamine hydrochloride (GH) on 22 ethological and physiological traits (not yet examined in humans) using ants as biological models. Here below, we explain why we used ants, which species we used, what we know on it, and which traits we intended to examine. Then, after having related our methods and results, we discuss about the opportunity of using glucosamine for treating arthritis, and conclude. 


\section{Using ants as models}

Physiological and ethological traits are similar for most animals and for humans. ${ }^{24}$ They are generally firstly examined on animals as models (e.g. fruit flies, cockroaches, bees, mice, monkeys) before being studied on humans. ${ }^{25}$ Insects are often used because they develop rapidly and are easily maintained in a laboratory. ${ }^{26}$ Hymenoptera, among others, are used ${ }^{27}$ and ants can advantageously be so. ${ }^{28}$ Indeed, ant colonies have social regulation, labor division, information exchange thanks to tactile and chemical signals (pheromones). ${ }^{29-31}$ They build sophisticated nests, care of their brood, chemically mark the different places of their habitat, ${ }^{29}$ navigate, recruit congeners, relocate their nest, clean its inside and create cemeteries. ${ }^{30}$ Their general biology makes them promising biological models, and the impact of products used by humans could be examined on them. ${ }^{32}$

\section{Which species we used}

We have largely studied the ants of the genus Myrmica, examining among others their ecology, eyes morphology, angle of vision, visual perception, recruitment strategy, navigation system, learning, ${ }^{33}$ and the ontogenesis of some of their abilities. ${ }^{34}$ The study of the effect of EMF on their conditioning, memory and responses to their pheromones revealed that they could be good biological models. ${ }^{35,36}$ This was confirmed when examining the impact of products used by humans [e.g. ${ }^{37-40}$. Each time, we revealed effects observed in humans and gave precision on them, and we pointed other ones from which humans may suffer. In the present work, we used again the ant $M$. sabuleti Meinert 1861 for studying the physiological and ethological effects of glucosamine.

\section{Which traits we examined}

We examined 18 traits firstly on ants living under normal diet then on these ants consuming glucosamine, and 4 other ones only on ants having consumed or consuming this drug. The 18 traits were: the ants' meat and sugar food consumption, general activity, speed of locomotion, sinuosity of movement, orientation ability, trail following, audacity, tactile (pain) perception, brood caring, aggressiveness towards nestmates and aliens, cognition, escaping ability, visual and olfactory conditioning, visual and olfactory memory. The 4 other traits were: the ants' adaptation to the adverse effects of the drug, habituation to its beneficial effects, dependence on its consumption, and the loss of its effects after consumption was stopped.

Adaptation to a product occurs when its adverse effects decrease over its consumption. Habituation to a product develops when its sought-after effect decrease over its consumption. Dependence on a product appears when an individual consuming it prefers a diet including this product to a diet free of it.

\section{Material and Methods}

\section{Remark}

Material and methods used were similar to those used in previous works. To limit plagiarism and long text, there are here briefly related, and readers are advised to find details in previous works, such as. ${ }^{37-40}$

\section{Collection and maintenance of ants}

The experiments were performed on two colonies of $M$. sabuleti collected in June 2018, from an abandoned quarry located at Marchin (Belgium), and on a third colony of the same species collected from the Aise Valley (Belgium) which furnished the aliens of the experiment on the ants' aggressiveness and the control values of the conditioning experiments. These colonies were maintained in two glass tubes half filled with water, and the nest tubes of each colony were deposited in a tray $(34 \mathrm{~cm} \times 23 \mathrm{~cm} \times 4 \mathrm{~cm}) \cdot{ }^{37-40}$ The ants were fed with pieces of Tenebrio molitor larvae (Linnaeus, 1758) delivered three times per week, and with sugar water permanently provided in cotton plugged tubes. The ambient temperature was $c a 20^{\circ} \mathrm{C}$, the humidity $80 \%$, the lighting $330 \mathrm{lux}$, and the electromagnetism $2 \mu \mathrm{Wm}^{2}$, all this being optimum for the species. The ants of the same colony are here often named 'nestmates'.

\section{Solution of glucosamine given to the ants}

Humans are advised to consume 1,500 $\mathrm{mg}$ of glucosamine per day for treating common arthritis. Humans drink about one liter of water per day. So, when using glucosamine for caring of themselves, humans consume $1,500 \mathrm{mg}$ of glucosamine together with one liter of water. Insects, and thus ants, consume about 10 less water than mammals. Consequently, for setting ants under a glucosamine diet similar to that of humans, they must be provided with an aqueous solution of $1,500 \mathrm{mg}$ of glucosamine in $100 \mathrm{ml}$ of water. A package of glucosamine hydrochloride 'Glucosamine 1500', marketed by 'Be-Life Natural Products' (Belgium; www.biolife.be) has been furnished by the pharmacist Wera (Bruxelles). This product contains glucosamine at $98 \%$ purity, issued from crustaceans. Using it, a solution of 1,500 $\mathrm{mg}$ of glucosamine hydrochloride in the sugar water usually given to the ants was made and kept at $-25^{\circ}$. After defrosting, $5 \mathrm{ml}$ of that solution were poured into tubes used to provide ants with sugar water, and such a tube was deposited in the tray of each two experimented colonies. Each day, it was checked if ants drunk the provided solution of glucosamine, and they did. Every 2-3days, the cotton plugs shutting the tubes were refreshed, and every 7 days, the entire content of the tubes was renewed.

\section{Food consumption, general activity}

The ants present on the T. molitor larvae, at the entrance of the sugar water tubes and being active anywhere on their foraging area and inside their nest were counted six times per day during six days, at the same times o'clock each day ( $\mathrm{as} \mathrm{in}^{40}$ among others). The mean of these daily counts was established (Table 1), and for each kind of counting, the average of the daily means was also calculated (Table 1 , last line).

\section{Linear and angular speeds, orientation to an alarm signal}

The assessments were made on ants walking in their foraging area, the speeds assessed without stimulating the ants, the orientation by stimulating the ants with a nestmate tied to a piece of white paper (Figure 1A). This tied nestmate emitted its attractive mandibular glands pheromone. As in previous works, [e.g. ${ }^{37-40}$ ] for the ants' speeds and separately for their orientation, the trajectory of 40 workers was recorded on a transparent sheet and analyzed thanks to appropriate software. ${ }^{41}$ The linear speed (in $\mathrm{mm} / \mathrm{s}$ ) is the length of a trajectory divided by the time spent to travel it. The angular speed (in angular degree $/ \mathrm{cm}=$ ang.deg. $/ \mathrm{cm}$ ) is the sum of the angles made by successive adjacent segments, divided by the length of the trajectory. The orientation (in ang. deg.) towards a given location is the sum of the successive angles made by the direction of the trajectory and that towards the location, divided by the number of measured angles. When the value of orientation is lower than $90^{\circ}$, the animal has a tendency to orient itself towards the location; when it is larger than $90^{\circ}$, the animal has a tendency to avoid the location. The median and quartiles of each distribution of 40 values were established (Table 2, lines $1,2,3)$. 
Table I Effect of glucosamine on food consumption and general activity

\begin{tabular}{lcccccc}
\hline $\begin{array}{l}\text { Colonies } \\
\text { A + B }\end{array}$ & Normal diet & \multicolumn{5}{c}{ Glucosamine diet } \\
\hline Days & meat & Sugar water & Activity & meat & Sugar water & Activity \\
\hline I & Daily means & & \multicolumn{5}{c}{ Daily means } \\
II & 0.67 & 0.75 & 10.90 & 0.58 & 0.67 & 13.50 \\
III & 0.58 & 0.75 & 10.08 & 0.58 & 1.25 & 14.92 \\
IV & 0.67 & 0.83 & 11.67 & 0.50 & 1.25 & 11.08 \\
V & 0.50 & 0.83 & 9.42 & 0.58 & 0.83 & 12.50 \\
VI & 0.58 & 1.00 & 11.92 & 0.58 & 1.17 & 9.25 \\
& 1.17 & 0.50 & 9.83 & 0.58 & 1.08 & 13.58 \\
I $\rightarrow$ VI & average of daily means & & average of daily means & 12.47 \\
\hline
\end{tabular}

The ants present on their meat, on their sugar water, and being active were counted 6 times per day. The daily means and the average of these means were established.The ants consuming glucosamine were more active than those living under normal diet. Details and statistics are given in the text.

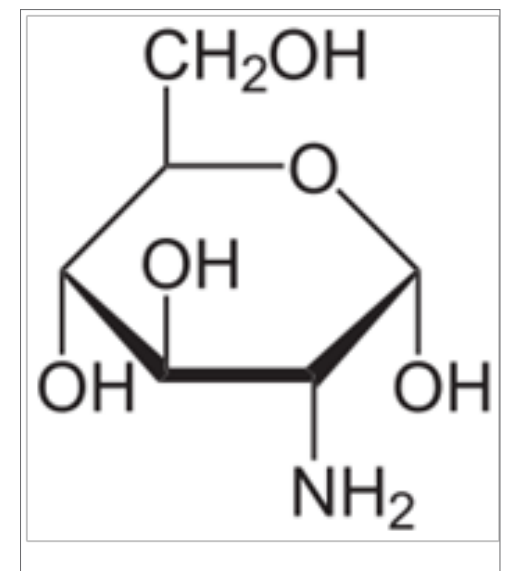

Figure I Chemical structure of glucosamine, a compound used for caring of humans suffering from osteoarthritis. Its efficiency and safety were recently debated. The present work examined its potential harmful effects on health using ants as biological models.

Table 2 Effect of glucosamine on six physiological or ethological traits

\begin{tabular}{|c|c|c|}
\hline Traits & $\begin{array}{l}\text { Sugar water } \\
\text { diet }\end{array}$ & $\begin{array}{l}\text { Sugar water + } \\
\text { glucosamine diet }\end{array}$ \\
\hline Linear speed (mm/s) & II.I (9.9- 12.2) & $12.9(\mid 1.0-14.6)$ \\
\hline Angular speed (ang.deg./cm) & $108(95-128)$ & $153(|40-| 7 \mid)$ \\
\hline Orientation (ang. deg.) & $38.4(26.7-54.9)$ & $43.8(33.9-63.4)$ \\
\hline Trail following ( $\mathrm{n}^{\circ}$ arcs) & $10.0(7.8-16.3)$ & $8.0(5.0-9.0)$ \\
\hline Audacity ( $\mathrm{n}^{\circ}$ ants) & $1.20[0-2]$ & $3.00[2-4]$ \\
\hline \multicolumn{3}{|l|}{ Tactile (pain) perception: } \\
\hline linear speed $(\mathrm{mm} / \mathrm{s})$ & $4.9(4.6-5.5)$ & $5.6(4.4-6.3)$ \\
\hline angular speed (ang.deg./cm) & $283(272-320)$ & $292(259-323)$ \\
\hline
\end{tabular}

Glucosamine increased the ants' linear and angular speeds, slightly reduced their trail following, and enhanced their audacity. Details and statistics are given in the text. $\mathrm{mm} / \mathrm{s}=$ millimeter per second; ang.deg=angular degree; ang . $\mathrm{deg} / \mathrm{cm}=$ angular degree per centimeter; $\mathrm{n}^{\circ}=$ number.

\section{Trail following}

The trail pheromone of M. sabuleti is produced by the workers' poison gland. Ten of these glands were thus isolated into $500 \mu 1$ of hexane as in previous works (e.g. $\mathrm{in}^{37-40}$ ), and the solution was then set for $15 \mathrm{~min}$ at $-25^{\circ} \mathrm{C}$. After that, using a normograph pen, $50 \mu \mathrm{l}$ of the solution was deposited on a circumference $(\mathrm{R}=5 \mathrm{~cm})$ pencil drawn on white paper and divided into arcs of 10 angular degrees. The obtained circular trail was set in the ants' tray and the behavior of ants reaching the trail was quantified by the number of arcs of 10 angular degrees 20 ants of each colony walked along the trail (Figure 2B). The distribution of the obtained 40 numbers was characterized by its median and quartiles (Table 2, line 4).

\section{Audacity}

As in previous works, ${ }^{37-40}$ a tower standing on a platform, both made of strong white paper (Steinbach ${ }^{\circledR}$, the tower height $=4 \mathrm{~cm}$; the tower diameter $=1.5 \mathrm{~cm}$ ), was presented to the ants, in their tray, and those present on the apparatus were counted 10 times over $10 \mathrm{~min}$ (Figure 2C). The mean and the extremes of the recorded numbers were established (Table 2, line 5). The numbers obtained for the two colonies as well as over two successive minutes were added.

\section{Tactile (pain) perception}

On a rough substrate, the ants correctly perceiving the uncomfortable character of the substrate walk cautiously, slowly and sinuously. If weakly perceiving this uncomfortable character, the ants move more quickly and less sinuously. Consequently, the ants' locomotion on a rough substrate allows evaluating their tactile perception. Such locomotion was thus assessed before and after the ants had consumed glucosamine for three days. As in previous works [e.g. ${ }^{37-40}$ ], a folded piece $(3 \mathrm{~cm} \times 2+7+2=11 \mathrm{~cm})$ of emery paper $\mathrm{n}^{\circ} 280$ paper was tied to the borders and the bottom of a tray $(15 \mathrm{~cm}$ $\times 7 \mathrm{~cm} \times 4.5 \mathrm{~cm}$ ) which became so divided into a first zone $3 \mathrm{~cm}$ long, a second one $3 \mathrm{~cm}$ long containing the emery paper, and a last one 9 $\mathrm{cm}$ long. Such an apparatus was built for each colony. To make the experiment, 12 ants of each colony were transferred into the first zone of their apparatus. They soon reached the rough substrate, and walked for a time on it (Figure 2D). Their linear and angular speeds were then assessed as usually (see above 'Linear and angular speeds') $(n=24$; Table 2, the two last lines). 


\section{Brood caring}

For each colony, a few larvae or nymphs were removed from the nest and deposited in front of the entrance. Five of these larvae or nymphs, as well as the ants' behavior towards them, were each time observed (Figure 2E). The larvae or nymphs among these observed and still not replaced in the nest were counted after $5 \mathrm{~s}, 2,4,6,8$, and $10 \mathrm{~min}$, and the numbers obtained for the two colonies were added (Table 3, line 1).

Table 3 Effect of glucosamine on five physiological and/or ethological traits

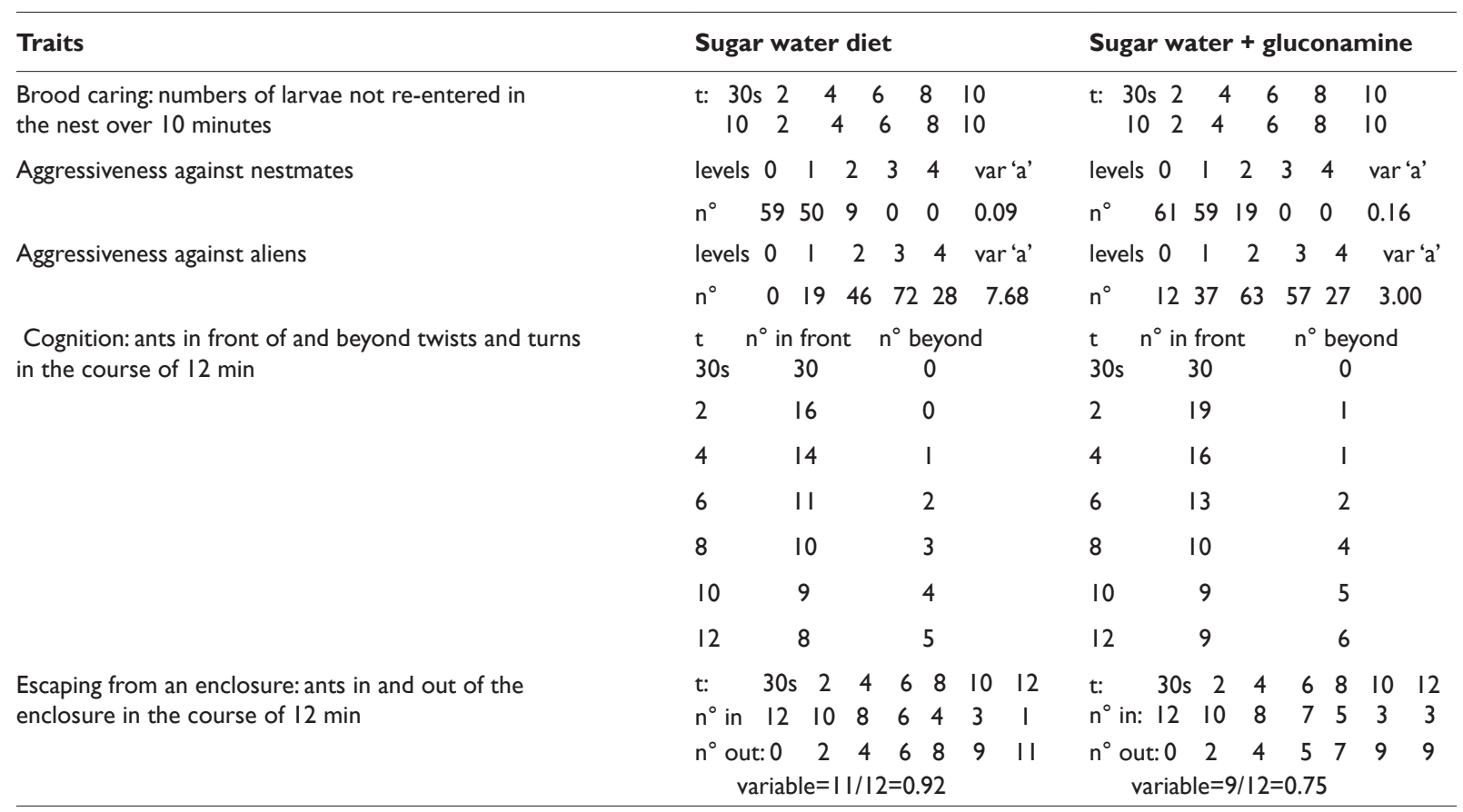

Glucosamine did not affect the ants' brood caring, aggressiveness against nestmates, cognition and escaping behavior. It only slightly reduced the ants' aggressiveness against aliens (through an increase of the ants' locomotion). Details and statistics are given in the text. $s=$ second; min $=$ minutes, $n^{\circ}=$ number; aggressiveness level $0=$ doing nothing, I=contacting the opponent with its antennae, $2=$ opening its mandibles, 3 =gripping the opponent, $4=$ trying to sting or stinging the opponent.

\section{Aggressiveness against nestmates and aliens}

Five dyadic encounters were performed, with either a nestmate or an alien ant, in a cylindrical cup (diameter $=2 \mathrm{~cm}$, height $=1.6 \mathrm{~cm}$, the borders being covered with talc), as in previous works [e.g. ${ }^{37-40}$. Each time, an ant of colony A or B was observed for 5min, and its behavior towards the encountered nestmate or alien was assessed by the number of times it did nothing (level 0 of aggressiveness), contacted the opponent with its antennae (level 1), opened its mandibles (level 2 ), gripped the other ant (level 3), tried to sting or stung the opponent (level 4) (Figure 2F, G). The numbers obtained for the two colonies were added (Table 3, lines 2,3). Moreover, as in previous works [e.g. $\left.{ }^{40}\right]$, the ants' aggressiveness was assessed by the variable "a" = number of aggressiveness levels $2+3+4$ / number of levels $0+1$.

\section{Cognition}

As made for the first time when studying the effects of nicotine, ${ }^{42}$ this trait was quantified using, for each colony, an adequate apparatus. Two pieces of white paper (Steinbach ${ }^{\circledR}, 12 \mathrm{~cm} \times 4.5 \mathrm{~cm}$ ) duly folded were inserted in a tray $(15 \mathrm{~cm} \times 7 \mathrm{~cm} \times 4.5 \mathrm{~cm})$ in order to divide this tray into a first small loggia, then a path with twists and turns, and finally a large loggia containing a piece of wet cotton. To make the experiment, 15 ants of each colony were transferred into the first loggia of their apparatus, and after $30 \mathrm{~s}, 2$, 4, 6, 8, 10 and $12 \mathrm{~min}$, those present in this loggia and in the large one were counted. The numbers obtained for the two colonies were added (Table 3, line 4).

\section{Escaping behavior}

As done in previous studies [e.g. ${ }^{37-40}$ ], for each colony, 6 ants were enclosed under a reversed polyacetate glass $(\mathrm{h}=8 \mathrm{~cm}$, bottom diameter
$=7 \mathrm{~cm}$, ceiling diameter $=5 \mathrm{~cm})$ deposited in the ants' tray. A notch ( $3 \mathrm{~mm}$ height, $2 \mathrm{~mm}$ broad) had been made in the rim of its bottom for allowing the ants escaping (Figure 2H). Then, after $30 \mathrm{~s}, 2,4,6,8,10$ and $12 \mathrm{~min}$, the escaped ants and those still enclosed were counted. The results obtained for the two colonies were added (Table 3, line 5). Moreover, the ants' ability in escaping was quantified by the variable ' $\mathrm{n}$ ' of ants escaped after $12 \mathrm{~min} / 12$ ', as done in previous works [e.g. $\left.{ }^{40}\right]$.

\section{Visual and olfactory conditioning and memory}

After the ants had consumed glucosamine for 7days, their conditioning and memorizing capabilities were assessed using a protocol many times employed [e.g..$\left.^{37-40}\right]$. The control values were those obtained during a previous study. ${ }^{43}$ In the present work, a green hollow cube was set above the entrance of the sugar water tube, and the ants started so to be visually conditioned to that green cube. After this visual conditioning experiment, pieces of basilica were set in front of the entrance of the sugar water tube, and the ants began so to be olfactory conditioned to basilica. Tests were performed after different time periods, first while ants were expected to acquire conditioning, then, after removal of the cue, while they were expected to lose their conditioning (Table 4). To make a test, 10 ants of colony $\mathrm{A}$ and of colony B were individually tested in their own Y-apparatus provided with a green hollow cube or with pieces of basilica in one of its branch (Figure 1I,J). The Y-apparatus made of strong white paper was deposited in a tray $(30 \mathrm{~cm} \times 15 \mathrm{~cm} \times 4 \mathrm{~cm})$. The cue set in this Y-apparatus was randomly located in the right or the left branch. Moving into the branch containing the cue was considered as giving the correct response. After each test, the response of 20 ants was obtained, and the proportion of correct responses could be calculated (Table 4). 
Table 4 Effect of glucosamine on the ants' visual and olfactory conditioning and memory

\begin{tabular}{|c|c|c|c|c|c|}
\hline \multirow{2}{*}{$\begin{array}{l}\text { Traits } \\
\text { time (h) }\end{array}$} & \multicolumn{3}{|c|}{ Normal diet * } & \multicolumn{2}{|c|}{ Glucosamine diet } \\
\hline & colony C & $\%$ & colony A & colony B & $\%$ \\
\hline \multicolumn{6}{|c|}{ Visual conditioning } \\
\hline 7 & 7 & 70 & 8 & 6 & 70 \\
\hline 24 & 8 & 80 & 8 & 8 & 80 \\
\hline 31 & 8 & 80 & 8 & 9 & 85 \\
\hline 48 & 8 & 80 & 9 & 9 & 90 \\
\hline 55 & 8 & 80 & 8 & 8 & 80 \\
\hline 72 & 8 & 80 & 8 & 8 & 80 \\
\hline \multicolumn{6}{|c|}{ Visual memory } \\
\hline 7 & 8 & 80 & 9 & 8 & 85 \\
\hline 24 & 7 & 70 & 8 & 8 & 80 \\
\hline 31 & 8 & 80 & 8 & 8 & 80 \\
\hline 48 & 7 & 70 & 8 & 8 & 80 \\
\hline 55 & 7 & 70 & 7 & 7 & 70 \\
\hline 72 & 7 & 70 & 7 & 7 & 70 \\
\hline \multicolumn{6}{|c|}{ Olfactory conditioning } \\
\hline 7 & 7 & 70 & 8 & 8 & 80 \\
\hline 24 & 8 & 80 & 8 & 9 & 85 \\
\hline 31 & 8 & 80 & 10 & 8 & 90 \\
\hline 48 & 9 & 90 & 9 & 7 & 80 \\
\hline 55 & 9 & 90 & 8 & 9 & 85 \\
\hline 72 & 9 & 90 & 8 & 10 & 95 \\
\hline \multicolumn{6}{|c|}{ Olfactory memory } \\
\hline 7 & 9 & 90 & 8 & 9 & 85 \\
\hline 24 & 8 & 80 & 8 & 8 & 80 \\
\hline 31 & 8 & 80 & 7 & 8 & 85 \\
\hline 48 & 7 & 70 & 8 & 8 & 80 \\
\hline 55 & 8 & 80 & 8 & 7 & 80 \\
\hline 72 & 8 & 80 & 8 & 6 & 75 \\
\hline
\end{tabular}

These traits were not impacted by glucosamine consumption. Details and statistics are given in the text. \%=proportion; $*=$ control results previously obtained. ${ }^{43}$ Adaptation to adverse effects of glucosamine,
habituation to beneficial effects of glucosamine

After the ants consumed glucosamine for 10days, a trait negatively affected and a trait positively impacted by this compound should be again assessed, as they had previously been, for examining if ants could adapt themselves to the negative effect, or became habituated to the beneficial impact of the drug. In the present work, the only trait affected by the examined drug was the ants' locomotion, i.e. their linear and angular speeds. These two variables were thus duly quantified and their median and quartiles established (Table 5).

Table 5 Adaptation and habituation to the effect of glucosamine on the locomotion

\begin{tabular}{llll}
\hline Traits & Normal diet & $\begin{array}{l}\text { Glucosamine diet since } \\
\text { one day }\end{array}$ & $\begin{array}{l}\text { Glucosamine diet since } \\
10 \text { days }\end{array}$ \\
\hline Linear speed $(\mathrm{mm} / \mathrm{sec})$ & $11.1(9.9-12.2)$ & $12.9(11.0-14.6)$ & $13.5(12.4-15.2)$ \\
Angular speed (ang.deg./cm) & $108(95-128)$ & $153(140-17 \mid)$ & $157(142-165)$ \\
\hline
\end{tabular}

The ants developed no adaptation (and no habituation) to the impact of glucosamine on their locomotion: values obtained after 10 days of consumption were similar to those obtained after one day of consumption. Details are given in the text. $\mathrm{mm} / \mathrm{sec}=\mathrm{millimeter}$ per second; ang.deg./cm=angular degree per centimeter.

\section{Dependence on glucosamine consumption}

This trait was examined after the ants had glucosamine at their disposal for 12days, using an experimental protocol already employed in previous studies [e.g. ${ }^{37-40}$ ]. For each colony, 15 ants were transferred into a tray $(15 \mathrm{~cm} \times 7 \mathrm{~cm} \times 5 \mathrm{~cm})$ containing a tube $(\mathrm{h}=2.5 \mathrm{~cm}$, diam. $=0.5 \mathrm{~cm}$ ) filled with sugar water, and another identical tube filled with the sugar solution of glucosamine used throughout all the present work (Figure 2K). The tube containing the drug was located on the right in one tray, and on the left in the other tray. The ants coming onto each tube were counted 15 times over $15 \mathrm{~min}$. The counts corresponding to each kind of liquid were separately added, and the counts obtained for the two colonies were added.

\section{Decrease of the effect of glucosamine after its consumption was stopped}

This was studied after the ants consumed glucosamine for a total of 17days and using an experimental protocol already employed in previous studies [e.g. ${ }^{37-40}$ ]. A fresh solution of the drug was given to the ants 12 hours before the weaning time, and the ants' sinuosity was assessed after these 12 hours, so just before the weaning time, i.e. at $\mathrm{t}=0 \mathrm{~h}$. Then, weaning started: the solution of glucosamine was replaced by a usual aqueous solution of sugar. Since this time, the ants' sinuosity was assessed each two hours, as it had been before the ants consumed glucosamine (= control), after they consumed the drug for one day, and after they consumed it for 10 days, except that only 20 instead of 40 ant's trajectories were analyzed for being able 
to make the assessments over the experimentation. The results are numerically given in Table 6 and graphically presented in Figure 3.
The experiment ended when the ants' sinuosity became similar to the control one.
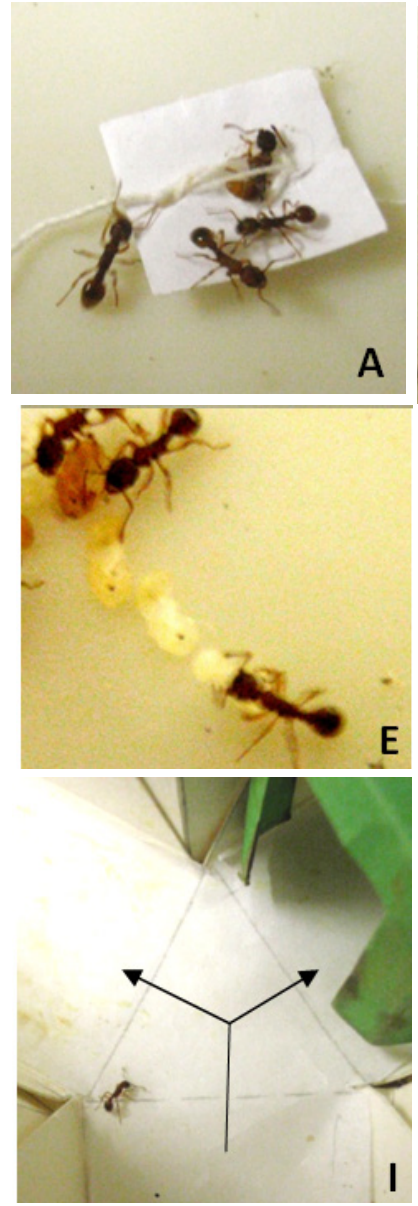

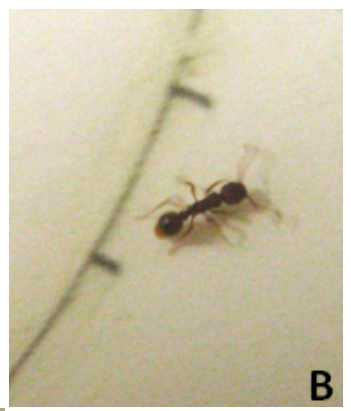

B

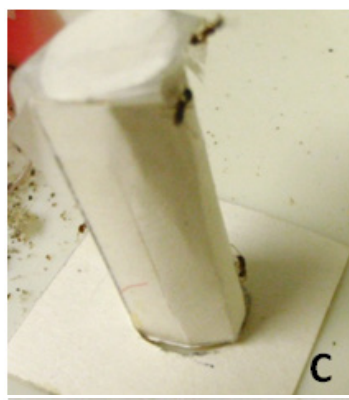

c
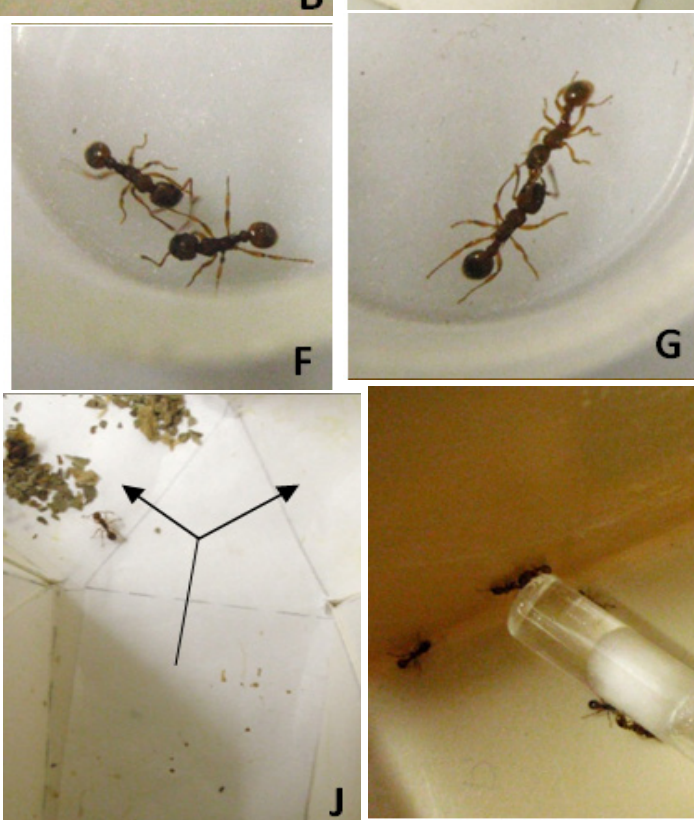

G
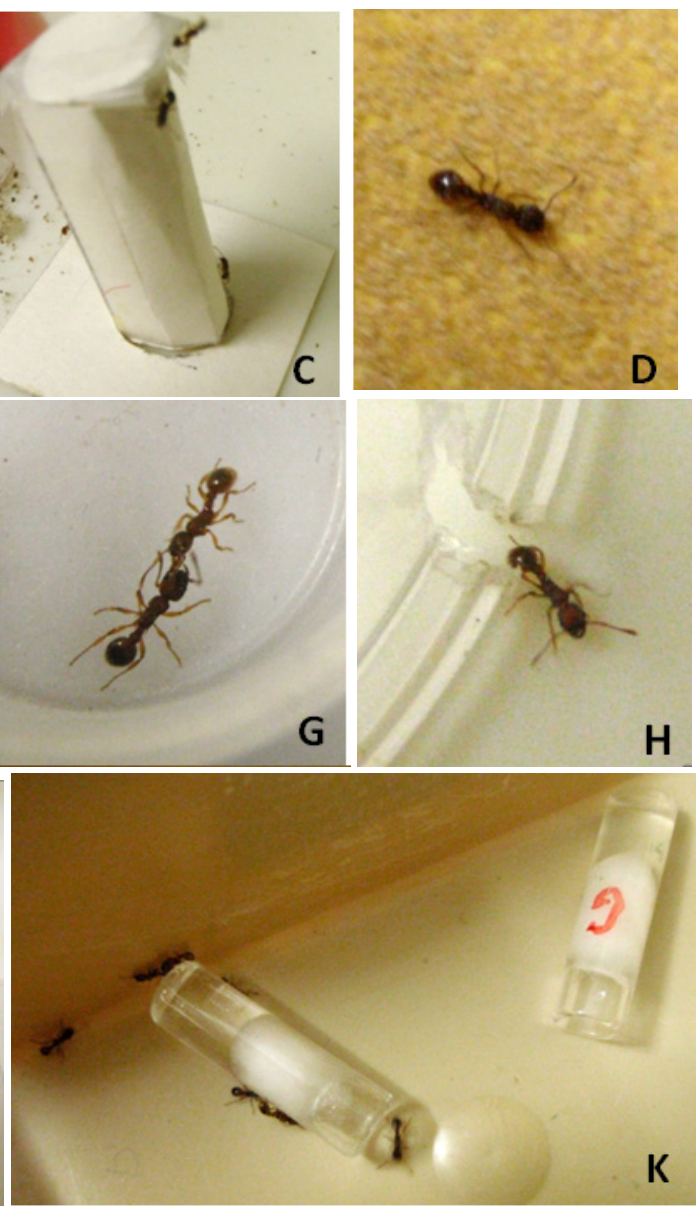

Figure 2 some views of the experiments. All photos are of ants consuming glucosamine except $\mathbf{E}$ which is of ants under normal diet. A: ants having reached a tied nestmate emitting its attractive alarm pheromone. B: an ant departing from a circular trail. C: three ants coming onto a risky apparatus. D: an ant walking with difficulty on a rough substrate. E: an ant retrieving a nymph experimentally removed from the nest and two other ants in the process of doing so. F: two nestmates without aggressiveness against one another. $\mathbf{G}$ : a nestmate gripping the mandible of an alien. $\mathbf{H}$ : an ant escaping from an enclosure into which it had been experimentally set. I: an ant trained to a green hollow cube in the nick of giving the correct response when tested in a Y-apparatus provided with that visual cue in one of its branch.J: an ant trained to basilica giving the correct response when tested in a Y-apparatus provided with that olfactory cue in one of its branch. K: ants preferring pure sugar water when having the choice between that water and sugar water containing glucosamine (tube with ' $G$ ' written in red). Black arrows: the two ways possible in the Y-apparatus.

\section{Statistical analyses}

Concerning the ants' food consumption and general activity, for each kind of counting, the six daily means obtained for ants consuming glucosamine were compared to the six daily means obtained for ants living under normal diet using the non-parametric test of Wilcoxon. ${ }^{44}$ The later test was also used to compare the ants' audacity, brood caring, cognition, escape behavior, as well as visual and olfactory conditioning and memory, under normal diet on one hand and under glucosamine diet on the other hand. As for the ants' linear speed, angular speed, orientation, trail following, tactile perception, aggressiveness against nestmates and against aliens, as well as adaptation (or habituation) to the observed effect of glucosamine, the statistical comparison between the two kinds of diet was made using the non-parametric $\chi^{2}$ test. ${ }^{44}$ For the ants' potential dependence on glucosamine consumption, the obtained summed numbers of ants were compared to the numbers expected if ants randomly went onto each kind of liquid, using the non-parametric goodness of fit $\chi^{2}$ test. ${ }^{44}$ The statistical analysis of the decrease of the effect of glucosamine after weaning was made as follows. The distributions of the 20 values obtained after given time periods were compared to that obtained at $\mathrm{t}=0 \mathrm{~h}$ and to the control one (the latter made of 40 values) using the non-parametric $\chi^{2}$ test. Moreover, using Statistica v.10 software, a non-parametric KruskalWallis one-tailed test ( $\mathrm{K}-\mathrm{W}$ test) for multiple comparisons was used to compare the values of sinuosity corresponding to times ranging from $\mathrm{t}=2 \mathrm{~h}$ to $\mathrm{t}=14 \mathrm{~h}$ after weaning to either the control values (made of 20 values out of 40 in such a way that the median and quartiles were similar to those of the 40 values) or the values at the beginning of weaning $(\mathrm{t}=0 \mathrm{~h})$, taking the two latter groups as control groups. ${ }^{44} \mathrm{~A}$ Bonferroni adjustment is incorporated.

The mathematical function describing the regression of the median value of the sinuosity on the time elapsed after weaning, was established using Statistica ${ }^{\circledR}$ V.10 software, and the choice between powers of polynomial regressions was established using the procedure described in Zar. ${ }^{45}$ Independently and for comparison purpose, a nonparametric local polynomial fitting was also made, using the function LOESS in R, with a span value of 0.5 and degree of local polynomials indiscriminately set at 1 or $2 .{ }^{46}$ 
Table 6 Decrease of the effect of glucosamine on the ants' locomotion after its consumption was stopped

\begin{tabular}{|c|c|c|c|c|c|}
\hline \multirow{3}{*}{$\begin{array}{l}\text { Experiments } \\
\text { and time (h) }\end{array}$} & \multirow{3}{*}{$\begin{array}{l}\text { Ants' sinuosity } \\
\text { ang.deg./cm }\end{array}$} & \multicolumn{4}{|c|}{ Statistics } \\
\hline & & \multicolumn{2}{|c|}{$\chi^{2}$} & \multicolumn{2}{|c|}{ K-W } \\
\hline & & vs control & $v s \mathrm{t}=0 \mathrm{~h}$ & vs control & $v s \mathrm{t}=0 \mathrm{~h}$ \\
\hline Control (normal diet) & $108(95-128)$ & & & & \\
\hline After I day of consumption & $153(|40-| 7 \mid)$ & & & & \\
\hline After 10 days of consumption & $157(\mid 42-165)$ & & & & \\
\hline \multicolumn{6}{|l|}{ After 17 days of consumption } \\
\hline$=$ just before weaning, $\mathrm{t}=0 \mathrm{~h}$ & $161(136-183)$ & $P<0.00 I$ & & $P<0.00 I$ & \\
\hline \multicolumn{6}{|l|}{ Weaning, } \\
\hline Time after weaning : $t=2 h$ & $150(\mid 40-184)$ & $P<0.001$ & $0.95<P<0.98$ & $P<0.001$ & $P=1$ \\
\hline $\mathrm{t}=4 \mathrm{~h}$ & $150(132-173)$ & $P<0.001$ & $0.95<P<0.98$ & $P<0.00 I$ & $P=1$ \\
\hline$t=6 h$ & $145(136-162)$ & $P<0.00 I$ & $0.30<P<0.50$ & $P<0.001$ & $P=1$ \\
\hline $\mathrm{t}=8 \mathrm{~h}$ & 142 (123-154) & $P<0.001$ & $0.30<P<0.50$ & $P=0.002$ & $P=0.42$ \\
\hline $\mathrm{t}=10 \mathrm{~h}$ & $135(125-146)$ & $P<0.001$ & $0.001<P<0.01$ & $P=0.028$ & $P=0.08$ \\
\hline $\mathrm{t}=\mathrm{I} 2 \mathrm{~h}$ & $126(97-136)$ & $0.02<P<0.05$ & $0.00 \mathrm{I}<\mathrm{P}<0.0 \mathrm{I}$ & $P=I$ & $P<0.001$ \\
\hline $\mathrm{t}=14 \mathrm{~h}$ & $111(89-124)$ & $0.80<P<0.90$ & $P<0.001$ & $P=1$ & $P<0.001$ \\
\hline$t=16 h$ & $102(89-131)$ & $0.80<P<0.90$ & $P<0.001$ & $P=1$ & $P<0.001$ \\
\hline
\end{tabular}

After weaning, the effect of glucosamine on the ants' sinuosity decreased, but the difference became significant only from 10 hours onwards. The effect fully vanished in a total of 14 hours. ang.deg./cm=angular degree per centimeter; $\mathrm{t}=$ time; $\chi^{2}=$ chi square test; $\mathrm{KW}=\mathrm{one}$-tailed non-parametric Kruskal-Wallis $\mathrm{ANOVA}$ for multiple comparisons, taking either 'control' or ' $t=0 \mathrm{~h}$ ' as control groups. The decrease pattern is graphically explained in Figure 3 .

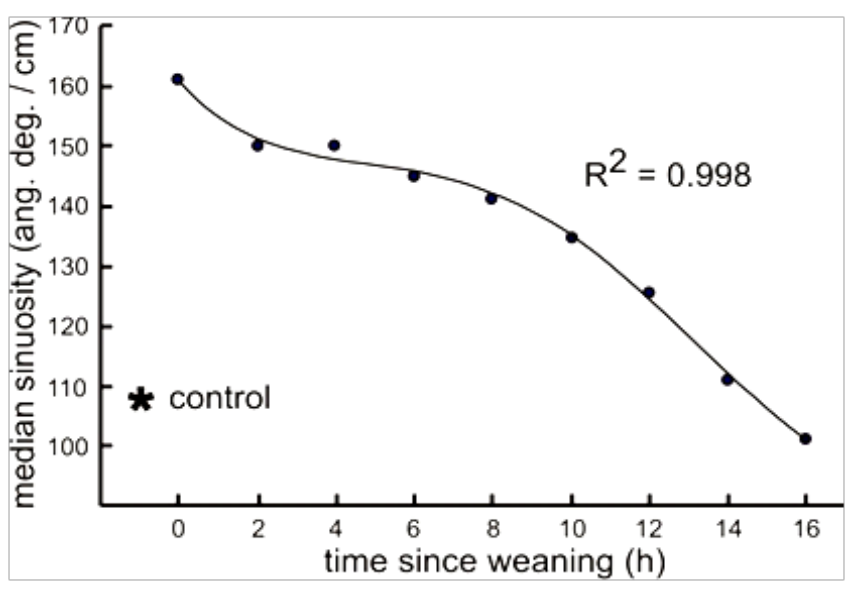

Figure 3 Decrease of the effect of glucosamine on the ants' sinuosity of movement after this drug consumption was stopped. The decrease of the effect slowed down till about 6hours, after what it accelerated and vanished in about 14 hours. On the whole, the slowness of the decrease is in agreement with the absence of dependence on glucosamine consumption. The whole decrease process fits to a fourth power polynomial function, detailed in the text. Numerical and statistical results are given in Table 6.

\section{Results}

\section{Food consumption, general activity}

These traits were somewhat affected by glucosamine consumption (Table 1). Ants under that drug diet consumed a little less meat than ants under normal diet (mean number of ants seen on the meat: $0.57 \mathrm{vs}$ $0.70)$, but this result was not statistically significant $(\mathrm{N}=4, \mathrm{~T}=+1,-9$, $\mathrm{P}=0.125)$. Ants under glucosamine diet consumed a little more sugar water than ants under normal diet (mean number of ants seen on the sugar water: $0.88 v s 0.78)$, a result at the limit of significance $(\mathrm{N}=5$, $\mathrm{T}=-1,+14, \mathrm{P}=0.063)$. Ants under glucosamine diet were more active than those under normal diet (mean number of active ants: 12.47 vs 10.64). This was obvious to the observer, although statistically only at the limit of significance $(\mathrm{N}=6, \mathrm{~T}=-3.5,+17.5, \mathrm{P}=0.093)$. Nevertheless, this increase in activity appeared sometimes as being spectacular and, later on, over the experimental work, was found to be an important effect leading to consequence (see below: 'Discussion').

\section{Linear and angular speeds}

While consuming glucosamine, the ants moved more rapidly and more sinuously than before consuming this drug (Table 2, lines 1,2). This result was statistically significant (linear speed: $\chi^{2}=11.60, \mathrm{df}=$ $2,0.001<\mathrm{P}<0.01$; angular speed: $\left.\chi^{2}=37.64, \mathrm{df}=2, \mathrm{P}<0.001\right)$. After the ants consumed glucosamine during 10 days, it was examined if they adapted (or became habituated) to this impact of the drug on their locomotion (see below 'Adaptation to adverse effects and habituation to beneficial effects of glucosamine').

\section{Orientation to an alarm signal}

Due to their modified locomotion (see just above), the ants consuming glucosamine had some difficulties in reaching the tied nestmate emitting its attractive alarm pheromone, though they were obviously attracted by such a substance (Figure 2A). Their orientation towards the alarm signal was lower than that presented before consuming glucosamine (43.8 vs 38.4 angular degrees; Table 2, line $3)$. However, this difference between the two kinds of diet was not significant $\left(\chi^{2}=4.27, \mathrm{df}=2,0.10<\mathrm{P}<0.20\right)$.

\section{Trail following}

While living under normal diet, the ants followed a circular trail along meanly 10 arcs of 10 ang. deg. While consuming glucosamine, they followed such a trail meanly only along 5 arcs of 10 ang.deg. (Table 2, line 4). This difference of trail following ability between the ants under one or the other kind of diet was significant $\left(\chi^{2}=12.75\right.$, $\mathrm{df}=3,0.001<\mathrm{P}<0.01)$. This is probably due to the larger linear and angular speeds of ants consuming glucosamine, what caused the ants' departure from the circular trail (Figure 2B). 


\section{Audacity}

Ants consuming glucosamine were more inclined to come on the unknown apparatus, and even to climb to the top of the tower, than ants living under normal diet (Fig. 2C). The numbers of ants counted on the apparatus in the course of the experimental time differed between the ants living under one and the other kind of diet (Table 2, line 5), and this difference was statistically significant $(\mathrm{N}=5, \mathrm{~T}=15$, $\mathrm{P}=0.031)$. This result was in agreement with the higher activity of ants consuming glucosamine (see above 'Food consumption, general activity') as well as with their enhanced locomotion (see above 'Linear and angular speeds').

\section{Tactile (pain) perception}

This trait was not affected by glucosamine consumption (Table 2, the two last lines; Figure 2D). Indeed, while living under normal diet as well as while consuming glucosamine, the ants moved very cautiously on a rough substrate, at a lower linear speed and a larger angular speed than on a common substrate. They also touched the substrate, in front of them, with their antennae. There was no difference of behavior (personal observation) and no statistical difference of locomotion on a rough substrate between the ants living under one or the other kind of diet (linear speed: $\chi^{2}=5.80, \mathrm{df}=2,0.05<\mathrm{P}<0.10$; angular speed: $\chi^{2}=0.92$, df $=2,0.50<\mathrm{P}<0.70$ ). As could be expected, the ants consuming glucosamine walked a little more rapidly than ants not consuming it $(5.6 \mathrm{vs} 4.9 \mathrm{~mm} / \mathrm{sec})$ due to the effect of the drug on their locomotion (see above 'Linear and angular speeds').

\section{Brood caring}

This trait was not affected by glucosamine consumption (Table 3, line 1; Fig. 2E). Ants living under normal as well as under glucosamine diets very quickly transported or tried to transport inside the nest the few larvae and nymphs experimentally removed from it. There was no statistical difference as for the numbers of not re-entered larvae between the ants consuming or not glucosamine $(\mathrm{N}=1, \mathrm{NS})$.

\section{Aggressiveness against nestmates}

Ants consuming glucosamine, just like those living under normal diet, never aggressed a nestmate (Table 3, line 2; Figure 2F). The behavior of these two kinds of ants during the experimental encountering was similar; the recorded numerical values did not statistically differ $\left(\chi^{2}=3.46, \mathrm{df}=2,0.10<\mathrm{P}<0.20\right)$. Thus, glucosamine did not impact the ants' social relationship, a result in agreement with that relative to brood caring (see above 'Brood caring').

\section{Aggressiveness against aliens}

In presence of an alien, the behavior of an ant consuming glucosamine slightly differed from that of an ant living under normal diet (Table 2, line 3; Figure 2G). While an ant under normal diet very quickly attacked the alien, an ant consuming glucosamine walked all around the experimental arena, and so, was more often attacked by the alien than it could itself, at first, attack the latter. The recorded numbers of aggressive acts of ants consuming glucosamine statistically differed from those numbers of ants not consuming that drug $\left(\chi^{2}=14.30, \mathrm{df}=\right.$ $3,0.001<\mathrm{P}<0.01$ ), and the variable assessing the aggressiveness of these two kinds of ants differed ( 3 vs 7.68).

\section{Cognition}

There was no difference as for this trait between the ants living under normal diet and those consuming glucosamine (Table 3, line 4).
Indeed, they similarly left the small area lying in front of the twists and turns path, and tried to cross this difficult path. Even if ants consuming glucosamine were somewhat more prompt to cross the difficult path (due to their higher audacity and locomotion), the difference with ants under normal diet was at the limit of significance (small area as well as large area: $\mathrm{N}=4, \mathrm{~T}=10, \mathrm{P}=0.063$ ).

\section{Escaping behavior}

This trait, affected in case of stress and/or reduced cognition, was not affected by glucosamine consumption (Table 3, last line; Figure $2 \mathrm{H})$. Having consumed or not this drug, the enclosed ants soon walked essentially along the rim of the enclosure, found the exit and went out. There was no statistical difference as for the numbers of ants still enclosed as well as escaped in the course of the experimental time (ants enclosed as well as escaped: $\mathrm{N}=3, \mathrm{NS}$ ). However, due to their increased locomotion, the ants consuming glucosamine walked more often rather quickly everywhere in the area under the reversed glass than slowly along its rim. Consequently, they escaped with some delay in comparison with ants not consuming this drug. The variable assessing the ants' ability in escaping equaled 0.75 for ants consuming glucosamine, and 0.92 for those not consuming this drug.

\section{Visual and olfactory conditioning and memory}

These traits were not affected by glucosamine consumption (Table 4). Concerning the visual conditioning (Fig. 2I), the ants consuming the drug acquired such a conditioning as quickly as ants living under normal diet and even reached a slightly higher level, but this small difference was not significant $(\mathrm{N}=3$, NS). After removal of the visual cue, ants consuming glucosamine kept their conditioning score during at least 31 hours, just like ants living under normal diet. After having no longer seen the visual cue since 72 hours, these two kinds of ants still responded to it with a score of $70 \%$. Even if ants consuming glucosamine presented somewhat better scores than those not consuming this drug, there was no statistical difference of visual memory between these two kinds of ants $(\mathrm{N}=3, \mathrm{NS})$.

As for the olfactory conditioning, the ants consuming glucosamine succeeded in acquiring it with successive scores similar to those presented by ants living under normal diet. The difference in conditioning capability between the two kinds of ants was not significant $(\mathrm{N}=6, \mathrm{~T}=-9,+12, \mathrm{P}=0.422)$. After removal of the olfactory cue, the ants consuming glucosamine progressively lost their conditioning like those living under normal diet though slightly more rapidly. This difference of memorizing between the two kinds of ants was not significant $(\mathrm{N}=4, \mathrm{~T}=-4,+6, \mathrm{P}=0.437)$ and could be explained by the slightly more rapid conditioning acquisition by ants consuming glucosamine (what is more quickly learned is also more rapidly forgotten).

\section{Adaptation to adverse effects and habituation to beneficial effects of glucosamine}

The only effect glucosamine had on the ants' physiology and ethology was the increase of their general activity and of their linear and angular speeds. This can be an adverse effect (by expending energy unnecessarily) or a beneficial one (by moving more quickly, they may increase their food collection, recruitment and transport of corpses). Consequently, some potential adaptation to adverse effects and some habituation to beneficial effects of the drug are, in the present case, the only and same event to study. The ants' linear and angular speeds were thus again quantified after 10days of glucosamine consumption. 
There was no adaptation, and no habituation, to the impact of glucosamine on the ants' locomotion (Table 5). After 10 days of the drug consumption, the ants' linear speed was still statistically larger than the usual one $\left(\chi^{2}=28.07, \mathrm{df}=3, \mathrm{P}<0.001\right)$, and statistically similar to that presented after one day of consumption $\left(\chi^{2}=0.89\right.$, df $=2,0.50<\mathrm{P}<0.70$ ). After 10days of glucosamine consumption, the ants' angular speed was still statistically larger than the usual one $\left(\chi^{2}\right.$ $=43.80, \mathrm{df}=2, \mathrm{P}<0.001)$, and statistically similar to that presented after one day of consumption $\left(\chi^{2}=0.60, \mathrm{df}=2,0.70<\mathrm{P}<0.80\right)$. Consequently, glucosamine increased the ants' locomotion (linear and angular speeds) and this effect persisted, unchanged, over the consumption time period. This was the only pointed effect of the drug. It was not excessive, it did not change (did not decrease nor increase) in the course of the drug use, and it may explain the nowadays debated effect of glucosamine (see below 'Discussion').

\section{Dependence on glucosamine consumption}

Ants living under a glucosamine diet did not develop dependence on that drug consumption, on the contrary. Twenty four ants of colony A were counted on the sugar water containing the drug, and 18 ones on the sugar water free of it. Only 12 ants of colony B were counted on the sugar water containing glucosamine, and 34 ones on the sugar water free of that drug. In total, 36 ants were thus seen on the liquid containing the drug and 52 ants were seen on the liquid free of the drug. These two numbers $(36,52)$ statistically differed from those expected $(44,44)$ if ants went randomly on the two liquids $\left(\chi^{2}=7.73\right.$, $\mathrm{df}=1,0.001<\mathrm{P}<0.01)$. The ants presented thus some tendency to avoid glucosamine and developed consequently no dependence at all on that drug.

\section{Decrease of the effect of glucosamine after its consumption was stopped}

We here primarily comment the decrease according to the results of Chi-square tests, but the reader is invited to look also at the results of ANOVA (Kruskal-Wallis) tests, both statistical results being exposed in Table 6.

During the first 6hours after weaning, the effect of glucosamine on the ants' sinuosity decreased in a slowing down motion (Figure 3), although being not significantly different from that before weaning (for the sixth hour: $\chi^{2}=2.20, \mathrm{df}=2,0.30<\mathrm{P}<0.50$ ) and still being very different from the control value $\left(\chi^{2}=23.32, \mathrm{df}=3, \mathrm{P}<0.001\right)$. After that, the decrease accelerated (Figure 3), though, at the $8^{\text {th }}$ hour, the sinuosity still remained statistically different from that just before weaning $\left(\chi^{2}=1.53\right.$, df $\left.=2,0.30<\mathrm{P}<0.50\right)$ and from the control one $\left(\chi^{2}=20.80, \mathrm{df}=3, \mathrm{P}<0.001\right)$. It means that glucosamine was still fully active eight hours after weaning. Ten hours after weaning, glucosamine began to be less active, the ants' sinuosity beginning to differ from that before weaning $\left(\chi^{2}=10.27\right.$, df $=2,0.001<\mathrm{P}<$ $0.01)$, although still differing from the control one $\left(\chi^{2}=21.91, \mathrm{df}=\right.$ $3, \mathrm{P}<0.001)$. Twelve hours after weaning, the effect of glucosamine weakened, being different from that before weaning $\left(\chi^{2}=12.01, \mathrm{df}=\right.$ $2,0.001<\mathrm{P}<0.01)$ and becoming (Kruskal-Wallis test) or tending to become non significant versus the control one $\left(\chi^{2}=6.80, \mathrm{df}=2,0.02\right.$ $<\mathrm{P}<0.05)$. Fourteen hours after weaning, glucosamine totally ceased to be active, the ants' sinuosity being then highly different from that before weaning $\left(\chi^{2}=15.96, \mathrm{df}=2, \mathrm{P}<0.001\right)$ and similar to the control one $\left(\chi^{2}=0.19\right.$, $\left.\mathrm{df}=2,0.90<\mathrm{P}<0.95\right)$. This is summarized in Table 6 , together with the numerical values and the results of KruskalWallis tests, and is graphically presented in Figure 3.
On the whole, the decrease of sinuosity was slow, which is in accordance with the absence of dependence on glucosamine consumption. A quadratic function describes the best the overall decrease of sinuosity over time, its equation being:

$$
y=160.556-7.0712 x+1.5869 x^{2}-0.1587 x^{3}+0.0046 x^{4}
$$

where $\mathrm{y}=$ median sinuosity (ang.deg./cm) and $\mathrm{x}=$ time (h) elapsed since weaning. Its determination coefficient equals 0.998 . This quadratic function agrees with a similar fit obtained using a local polynomial regression.

The decrease of the effect of glucosamine after weaning occurred thus in two successive steps: a first one, slowing down over time, and a second one, accelerating over time. This might correspond to two successive hypothetic physiological events: firstly, the elimination of glucosamine present in the ants' hemolymph, and after that, the elimination of glucosamine present in the other tissues.

\section{Discussion}

No adverse effect of glucosamine consumption on the ants' physiology and ethology was found, at least as for the different traits examined and using a dose corresponding to a human standard one. Several traits were not at all affected: the tactile perception, brood caring, aggressiveness against nestmates, cognition, escape behavior, as well as the visual and olfactory conditioning and memory. This is in agreement with the estimated safety of glucosamine as used by humans; cell's death occurred only when large doses of the drug were used (see the introduction section). The only observed impact on ants was their increase of general activity, and of movement (linear and angular speeds). Such an increase slightly affected a few of the ants' examined traits: their orientation, trail following, audacity, and aggressiveness against aliens. The effect of glucosamine on the ants' activity and locomotion stayed intact over the drug consumption, the ants developed no dependence on glucosamine consumption, and the effect of this drug slowly decreased after weaning, vanishing in about 14 hours; these observations are in agreement with one another (explanation in $^{28}$ ).

About the efficiency of glucosamine for caring of patients suffering from arthritis, it is known that the consequences of this disease can be somewhat mitigated by the moving of articulations, by walking or making movements, and never staying motionless for a long time period. ${ }^{47,48}$ We hypothesize thus that the efficiency of glucosamine could, at least partly, result from its incitement in moving.

The functional properties of cartilage rely on its extracellular matrix and on its tissue fluid, which amounts to $60 \%$ to $80 \%$ of the cartilage wet weight. This fluid contains a large amount of water loosely bound to the proteoglycans which release it under external pressure. ${ }^{49}$ This contributes to the resilience and elasticity of the cartilage as well as to the lubrication of the joint $t^{1,2}$. Therefore, a correct hydration and pressure avoidance can help patients suffering from arthritis. Moreover, a synergistic action of antioxydant vitamins (C and D), of selenium as part of an antioxidant enzyme and of omega-3 fatty acids, these last compounds being known for their anti-inflammatory properties, can be used as auxiliaries to chondroprotectives in the struggle against osteoarthritis. ${ }^{1}$

\section{Conclusion}

No adverse effect was induced in the ants' physiology and ethology by glucosamine consumption, except an increase of movement, which 
may be, in fact, a beneficial effect since arthritis can be cared by avoiding staying motionless. Since medicinal studies show that the efficiency of chondroprotective substances such as glucosamine and chondroitin in the treatment of arthritis is at the most modest, moderate movements, besides adequate hydration of tissues and avoidance of high pressure on the cartilage can usefully help for caring of persons suffering from this disease. Complementary treatments suggested in the literature, such as the intake of antioxydant vitamines and minerals, and of anti-inflammatory omega- 3 fatty acids can also be helpful.

\section{Acknowledgements}

None.

\section{Conflict of interest}

We affirm having no conflict of interest as for the use or the disregarding of glucosamine. We are ethologists, working on ants, and receive no money for making our research.

\section{References}

1. Jerosch J. Effects of Glucosamine and Chondroitin Sulfate on Cartilage Metabolism in OA: Outlook on Other Nutrient Partners Especially Omega-3 Fatty Acids. International Journal of Rheumatology. 2011; Article ID 969012:1-17.

2. James CB, Uhl TL. A Review of Articular Cartilage Pathology and the Use of Glucosamine Sulfate. J Athl Train. 2001;36(4):413-419.

3. Owens S, Wagner P, Vangsness C Jr. Recent Advances in Glucosamine and Chondroitin Supplementation. J Knee Surg. 2004;17(4):185-193.

4. Muniyappa R, Karne RJ, Hall G, et al. Oral Glucosamine for 6 Weeks at Standard Doses Does Not Cause or Worsen Insulin Resistance or Endothelial Dysfunction in Lean or Obese Subjects. Diabetes. 2006;55(11):3142-3150.

5. Christgau S, Henrotin Y, Tankó LB, et al. Osteoarthritic patients with high cartilage turnover show increased responsiveness to the cartilage protecting effects of glucosamine sulphate. Clin Exp Rheumatol. 2004;22(1):36-42.

6. Petersen SG, Saxne T, Heinegard D, et al. Glucosamine but not ibuprofen alters cartilage turnover in osteoarthritis patients in response to physical training. Osteoarthritis and Cartilage. 2010;18(1):34-40.

7. Reginster JY, Deroisy R, Rovati LC, et al. Long-term effects of glucosamine sulphate on osteoarthritis progression: a randomised, placebo-controlled clinical trial. Lancet. 2001;357(9252):251-256.

8. Pavelká K, Gatterová J, Olejarová M, et al. Glucosamine Sulfate Use and Delay of Progression of Knee Osteoarthritis. Arch Int Med. 2002;162(18):2113-2123.

9. Hochberg MC, Martel-Pelletier J, Monfort J, et al. Combined chondroitin sulfate and glucosamine for painful knee osteoarthritis: a multicentre, randomised, double-blind, non-inferiority trial versus celecoxib. Ann Rheum Dis. 2006;75(1):37-44.

10. Rozendaal RM, Koes BW, van Osch GJVM, et al. Effect of Glucosamine Sulfate on Hip Osteoarthritis. Ann Intern Med. 2008;148(4):268-277.

11. Rozendaal RM, Uitterlinden EJ, Van Osch GJVM, et al. Effect of glucosamine sulfate on joint space narrowing, pain and function in patients with hip osteoarthritis; subgroup analyses of a randomized controlled trial. Osteoarthritis and Cartilage. 2009;17(4):427-432.

12. Clegg DO, Reda DJ, Harris CL, et al. Glucosamine, Chondroitin Sulfate, and the Two in Combination for Painful Knee Osteoarthritis. The New
England Journal of Medicine. 2006;354(8):795-808.

13. Sawitzke AD, Shi H, Finco MF, et al. Clinical efficacy and safety over two years use of glucosamine, chondroitin sulfate, their combination, celecoxib or placebo taken to treat osteoarthrits of the knee: a GAIT report. Ann Rheum Dis. 2010;69(8):1459-1464.

14. $\mathrm{Wu} \mathrm{D}$, Huang Y, Gu Y, et al. Efficacies of different preparations of glucosamine for the treatment of osteoarthritis: a meta-analysis of randomised, double-blind, placebo-controlled trials. Clinical Practice. 2013;67(6):585-594.

15. Wandel S, Juni P, Tendal B, et al. Effects of glucosamine, chondroitin, or placebo in patients with osteoarthritis of hip or knee: network metaanalysis. BMJ. 2010;341:c4675.

16. Vlad C, La Valley MP, McAlindon TE, et al. Glucosamine for Pain in Osteoarthitis: Why Do Trial Results Differ? Arthritis and Rheumatism. 2007;56 (7):2267-2277.

17. Lee YH, Woo JH, Choi SJ, et al. Effect of glucosamine or chondroitin sulfate on the osteroarthritis progression: a meta-analysis. Rheumatology International. 2010;30(3):357-363

18. Bruyere O, Pavelká MD, Rovati LC, et al. Total joint replacement after glucosamine sulphate treatment in knee osteoarthritis: results of a mean 8-year observation of patients from two previous 3-year, randomised, placebo-controlled trials. Osteoarthritis and Cartilage. 2008;16(2):254 260.

19. Sawitzke AD, Shi H, Finco MF, et al. The effect of Glucosamine and/or Chondroitin Sulfate on the Progression of Knee Osteoarthritis. A Repor from the Glucosamine/Chondroitin Arthritis Intervention Trial. Arthritis \& Rheumatism. 2008;58(10):3183-3191.

20. Anderson JW, Nicolosi RJ, Borzelleca JF. Glucosamine effects in humans : a review of effects on glucose metabolism, side effects, safety considerations and efficacy. Food and Chemical Toxicology. 2005;43(2):187-201

21. Balkan B, Dunning BE. Glucosamine Inhibits Glucokinase In Vitro and Produces a Glucose-Specific Impairment of In Vivo Insulin Secretion in Rats. Diabetes. 1994;43(10):1173-1179.

22. Monauni T, Zenti MG, Cretti A, et al. Effects of Glucosamine Infusion on Insulin Secretion and Insulin Action in Humans. Diabetes. 2000;49(6):926-935.

23. Lafontaine-Lacasse M, Doré G, Picard F. Hexosamines stimulate apoptosis by altering SIRT1 action and levels in rodent pancreatic $\beta$-cells. J Endocrinol. 2011;208(1):41-49.

24. Sherwood L, Klandorf H, Yancey P. Physiologie animale. De Boeck superieur, Editor. Belgium; 2016:904p.

25. Bousquet C. Bêtes de science. Seuil. 2003:240p

26. Wolf FW, Heberlein U. Invertebrate models of drug abuse. J Neurobiol. 2003;54(1):161-178.

27. Andre RG, Wirtz RA, Das YT. Insect Models for Biomedical Research In: Woodhead AD, editor. Non mammalian Animal Models for Biomedical Research. Florida, Boca Raton: CRC Press. 1989;62-70.

28. Cammaerts MC. Physical dependence on a substance occurs when the effect of this substance rapidly decreases after withdrawal. JSM Anat Physiol. 2018;3(1):1017.

29. Hölldobler B, Wilson EO. The ants. Berlin, Heidelberg: Springer-Verlag; 1990:732 p.

30. Passera L, Aron S. Les fourmis: comportement, organisation sociale et évolution. NRC Research Press. 2005:480p. 
31. Billen J, Morgan ED. Pheromone communication in social insects sources and secretions. In: Vander Meer RK, Breed MD, Espelie KE, Winston MLK editors. Pheromone Communication in Social Insects: Ants, Wasps, Bees, and Termites; Westview Press: Boulder, Oxford, 1998;1:3-33.

32. Cammaerts MC. Some findings on ants as models, which should be considered for caring of humans. MOJ Biol Med. 2017;1(5): 00027.

33. Cammaerts MC, Cammaerts D. Comparative outlook over three Myrmica species' biotopes and foragers' know-how. Biologia. 2014;69:1051-1058.

34. Cammaerts MC, Cammaerts R. Ontogenesis of ants' cognitive abilities (Hymenoptera, Formicidae). Adv Stud Biol. 2015;7:335-348.

35. Cammaerts MC, De Doncker P, Patris X, et al. GSM $900 \mathrm{MHz}$ radiations inhibits ants' association between food sites and encountered cues. Electrom Biol Med. 2012;31:151-165.

36. Cammaerts MC, Rachidi Z, Bellens F, et al. Food collection and responses to pheromones in an ant species exposed to electromagnetic radiation. Electrom Biol Med. 2013;33:282-288.

37. Cammaerts MC, Cammaerts D. Physiological and ethological effects of fluoxetine, on ants used as biological models. Int J Biol. 2015;7 (2):1-18.

38. Cammaerts MC, Cammaerts R. Ethological and physiological effects of the recently most used analgesic, ibuprofen; a study on ants as models. EC Pharmacol Toxicol. 2018;6(4):251-267.

39. Cammaerts MC. Physiological and Ethological Effects of Glutathione, a Powerful Antioxidant Food Complement; A Study on Ants as Models. MOJ Biol Med. 2017;2(2):00045.
40. Cammaerts MC, Cammaerts R. Ants as models for assessing the effects on health of a $\mathrm{CaCO}_{3}+\mathrm{MgCO}_{3}$ mixture used to decrease gastric hyperacidity. EC Nutrition. 2018;13(7):500-514.

41. Cammaerts MC, Morel F, Martino F, et al. An easy and cheap softwarebased method to assess two-dimensional trajectories parameters. Belg $J$ Zool. 2012;142:145-151.

42. Cammaerts MC, Gosset G, Rachidi Z. Some physiological and ethological effects of nicotine; studies on the ant Myrmica sabuleti as a biological model. Int J Biol. 2014;6(4):64-81.

43. Cammaerts MC, Cammaerts D. Physiological effects of statines; a study on ants as models. A J Pharm Res Health Care. 2017;9(4):145-157.

44. Siegel S, Castellan NJ. Non-parametric statistics for the behavioural sciences. Singapore: McGraw-Hill Book Company;1989: 396p.

45. Zar JH. Biostatistical analysis, Prentice-Hall, Inc., New Jersey; USA: Upper Saddle River; 1999: 663p.

46. http://www.R-project.org.

47. Fransen M, McConnell S, Bell M. Exercise for osteoarthritis of the hip or knee. Cochrane Database Syst Rev. 2003;(23):CD004286.

48. Jamtvedt G, Dahm KT, Christie A, et al. Physical Therapy Interventions for Patients With Osteoarthritis of the Knee: An Overview of Systematic Reviews. Phys Ther. 2008;88(1):123-136.

49. Lamure A, Harmand MF, Lacabanne C. Micromechanical spectroscopy of cartilage proteoglycans: Hydration. $J$ Biomed Mater Res. 1990;24(6):735-747. 